\title{
Griffonia simplicifolia I Lectin Mediates Macrophage-Induced Cytotoxicity against Ehrlich Ascites Tumor
}

\author{
Daniel E. Maddox, ${ }^{*, 1}$ Irwin J. Goldstein, $\dagger$ and Albert F. Lobuglio $\ddagger^{2}$ \\ Department of Internal Medicine, Sections of *Allergy and Clinical Immunology, \\ and $\ddagger$ Hematology/Oncology, and the $†$ Department of Biological Chemistry, \\ University of Michigan Medical School. Ann Arbor, Michigan 48109
}

Received May 3, 1982; accepted May 20, 1982

\begin{abstract}
The concurrent administration of Griffonia simplicifolia lectin into the peritoneal cavity of mice has been reported to protect them from challenge with Ehrlich ascites tumor cells. This study demonstrates that the GS I lectin is capable of binding to the surface of both inflammatory macrophages and Ehrlich ascites tumor cells and can mediate macrophage lectin-dependent cytotoxicity to this tumor cell line. The lectin was not found to be toxic to Ehrlich ascites tumor cells directly or to nonspecifically initiate complement-mediated lysis of these target cells. The macrophage lectin-dependent cytotoxicity could be specifically inhibited by the haptenic sugar methyl $\alpha$-D-galactopyranoside. Thus, this lectin appears to be able to provide a linkage between effector macrophages and Ehrlich ascites tumor cells resulting in the triggering of a cytolytic event.
\end{abstract}

\section{INTRODUCTION}

We are interested in the glycoproteins expressed on cell surfaces and are using lectins as tools for their characterization and isolation. A unique family of $\alpha$-Dgalactosyl binding isolectins from Griffonia simplicifolia seeds has occupied our attention for the past decade (1-4). We have isolated and characterized these lectins (GS I isolectins), studied their physicochemical properties, and investigated their interaction with a variety of normal and malignant cells (2-6). These lectins have a $M_{\mathrm{r}}$ of 114,000 and have four combining sites for $\alpha$-D-galactosyl moieties on cell surface glycoproteins.

Using fluorescein- and ferritin-labeled $G$. simplicifolia $\mathrm{I}-\mathrm{B}_{4}$ isolectin in conjunction with coffee bean $\alpha$-galactosidase, we have demonstrated the presence of terminal $\alpha$-D-galactosyl residues on the cell surface of Ehrlich ascites tumor (EAT) cells and succeeded in isolating a family of $\alpha$-D-galactosyl-containing glycoproteins from their detergent-solubilized cell membranes (5). In exploring what effects these lectins might have on EAT cells in vivo, we discovered that simultaneous administration of an aqueous solution of GS I lectin at the time of inoculation of mice with $10^{7}$ EAT cells $\left(\mathrm{LD}_{100}\right)$ resulted in complete protection of the animals from

\footnotetext{
${ }^{1}$ Present address: Allergic Diseases Research Laboratory, Mayo Clinic and Foundation, Rochester, Minn. 55905.

${ }^{2}$ To whom reprint requests should be addressed.
} 
tumor growth and subsequent mortality (4). The studies reported in this paper were undertaken to examine some of the potential mechanisms responsible for this observed lectin effect.

Using an in vitro cell cytotoxicity assay, we tested three hypotheses: (i) lectin is directly toxic to the EAT cell, (ii) lectin activated complement after binding to the cell surface, resulting in complement-mediated cell lysis, and (iii) lectin somehow interacts with host immune effector cells, resulting in lectin-mediated cellular cytotoxicity to tumor targets. We selected macrophages as the effector cell for initial examination, inasmuch as concurrent work indicated the presence of a GS I receptor on stimulated murinc macrophages (7).

\section{MATERIALS AND METHODS}

Animals. CD-1 strain white male mice (Charles River) were used as a source of macrophages, and also for passage of the EAT cells.

Macrophages. Macrophages were obtained by peritoneal lavage according to previously described methods (7) on the fifth day following peritoneal injection of $1.5 \mathrm{ml}$ thioglycollate broth. Assessment of these cell populations by nonspecific esterase staining (8) indicated greater than $95 \%$ of cells were macrophages, which correlated closely with Wright-Giemsa cytospin differentials indicating 90-95\% of cells were macrophages. Viability of cells by trypan blue (Sigma, St. Louis, Mo.) exclusion was greater than $97 \%$.

Lectins. GS I isolectins were isolated and purified by methods previously described $(3,9)$.

Sugars. The haptenic sugar methyl $\alpha$-D-galactopyranoside and the nonhaptenic sugar methyl $\alpha$-D-glucopyranoside were obtained from Pfanstiel Laboratories, Inc., Waukegan, Ill.

Tumor target cells. Mice were inoculated intraperitoneally with EAT cells in suspension, and sacrificed on the fourteenth postinoculation day. The grossly distended abdominal cavity was tapped by passage of an 18-gauge needle through the skinned abdominal wall, with aspiration of the ascitic fluid. The cells were washed three times with buffer (Seligman's balanced salt solution $\mathrm{Ca}^{2+}-\mathrm{Mg}^{2+}$-free) (Microbiological Associates, Bethesda, Md.), labeled with ${ }^{51} \mathrm{Cr}$ as previously described (10) and resuspended to a concentration of $2 \times 10^{5} / \mathrm{ml}$ in RPMI 1640 containing $10 \%$ fetal calf sera (hereafter referred to as complete media). Viability of this labeled tumor cell preparation by trypan exclusion was routinely greater than $97 \%$ and cytospin differentials evaluated with Wright-Giemsa staining revealed less than $0.1 \%$ contamination by other cell types (lymphocytes, monocytes, macrophages, or PMNs). The spontaneous release of ${ }^{51} \mathrm{Cr}$ from this labeled tumor population under the conditions of the assays described below was routinely $3-4 \%$ of total counts at $4 \mathrm{hr}$ and $29-31 \%$ of total counts at $18 \mathrm{hr}$ of incubation. Release of ${ }^{51} \mathrm{Cr}$ correlated well with viability estimated by trypan exclusion.

Lectin-mediated cytolysis. The direct effect of GS I lectin was determined by incubating $2 \times 10^{4}{ }^{51} \mathrm{Cr}$-labeled EAT cells with varying concentrations of lectin, with and without haptenic or nonhaptenic sugars (final concentrations of $10 \mathrm{mM}$ ). The incubations were carried out in triplicate microwells in a total volume of 300 $\mu \mathrm{l}$ of complete media for 4 and $18 \mathrm{hr}$ at $37^{\circ} \mathrm{C}$. The percentage cytotoxicity was calculated by the formula: 


$$
\% \text { cytotoxicity }=\frac{(A-B)}{(C-B)} \times 100
$$

where $A=\mathrm{cpm}$ released from EAT cells + lectin, $B=\mathrm{cpm}$ released from EAT cells alone, and $C=$ total cpm of labeled EAT cells.

Complement-mediated cytolysis. Fresh mouse serum was added to $2 \times 10^{4}{ }^{51} \mathrm{Cr}$ labeled EAT cells to a final concentration of $3 \%$ (by volume) in triplicate microwells in the presence of varying concentrations of lectin $(0-100 \mu \mathrm{g} / \mathrm{ml})$ and ${ }^{51} \mathrm{Cr}$ release was examined at 4 and $18 \mathrm{hr}$.

Additionally, a similar range of concentrations of GS I was added to fresh human sera, incubated for $1 \mathrm{hr}$, and then the serum assayed for total hemolytic complement.

Cell cytotoxicity assay. ${ }^{51} \mathrm{Cr}$-labeled EAT cells $\left(2 \times 10^{4}\right)$ were distributed in microtiter wells (CoStar, Cambridge, Mass.) along with varying numbers of macrophages to achieve effector/target $(\mathrm{E} / \mathrm{T})$ ratios of $5: 1$ to $40: 1$. GS I lectin was added to wells to achieve final concentrations which varied from 0 to $100 \mu \mathrm{g} / \mathrm{ml}$. After addition of cells, the plates were centrifuged briefly at low speed $(100 \mathrm{~g})$. Incubations were carried out 4 and $18 \mathrm{hr}$ at $37^{\circ} \mathrm{C}$ in $5 \% \mathrm{CO}_{2}$ atmosphere. Cytotoxicity at each lectin concentration was calculated by the formula:

$$
\% \text { cytotoxicity }=\frac{(A-B)}{(C-B)} \times 100
$$

where $A=\mathrm{cpm}$ in supernatant solution of macrophages and EAT cells at that lectin concentration; $B=\mathrm{cpm}$ in supernatant of EAT cells alone at that lectin concentration; and $C=$ total $\mathrm{cpm}$ in EAT cells.

To demonstrate the specificity of the lectin-mediated lysis, haptenic and nonhaptenic sugars were added to wells at a final concentration of $10 \mathrm{mM}$ to determine their ability to inhibit lysis.

Fluorescein-conjugated lectin staining of cells. GS I was conjugated with fluorescein isothiocyanate by methods previously described (6). Cell labeling has been reported in detail elsewhere (7). Briefly, approximately $10^{6}$ cells suspended in $1 \mathrm{ml}$ normal saline made $0.1 \%$ in sodium azide (Fisher Scientific Co., Detroit, Mich.) and $20 \mu \mathrm{g} / \mathrm{ml}$ of FITC-GS I were incubated for $30 \mathrm{~min}$ at room temperature. Cells were then washed by four centrifugations in saline, incubated with $2 \%$ paraformaldehyde (Sigma Chemical Co., St. Louis, Mo.) for $15 \mathrm{~min}$, and then sealed under cover slips for viewing by fluorescence microscopy. Photographs were made using the built-in camera in a Zeiss Ultraphot III photomicroscope, equipped with uv epi-illumination.

\section{RESULTS}

Table 1 presents the results of direct lectin effects on lysis of EAT cells at 4 and $18 \mathrm{hr}$ of incubation. Little or no ${ }^{51} \mathrm{Cr}$ release occurred at any lectin concentration tested. The sugars also had no effect on ${ }^{51} \mathrm{Cr}$ release. Thus, the lectin does not appear capable of direct lysis or killing of EAT cells.

In studies of the effects of lectin on complement lysis of target cells, the addition. of lectin over a wide range of concentrations produced no increase in ${ }^{51} \mathrm{Cr}$ release from EAT cells in the presence of fresh mouse sera (data not shown). Further, the addition of lectin (in concentrations of $1-100 \mu \mathrm{g} / \mathrm{ml}$ ) to fresh human serum failed to alter the hemolytic complement activity of the sera. 
TABLE 1

Direct Cytotoxicity ${ }^{a}$ of EAT by $G$. simplicifolia Lectin ( \pm Sugars)

\begin{tabular}{lrrrrr}
\hline & \multicolumn{5}{c}{ Lectin concentration $(\mu \mathrm{g} / \mathrm{ml})$} \\
\cline { 2 - 6 } Sugars & \multicolumn{6}{c}{0} & 0.1 & 1.0 & 10.0 & 100.0 \\
\hline None & 0 & 0 & 1 & 1 & -4 \\
Me $\alpha-\mathrm{Gal}^{b}$ & -2 & 0 & 0 & 1 & 0 \\
Me $\alpha-\mathrm{Glc}^{b}$ & -4 & -1 & -3 & -2 & -6 \\
\hline
\end{tabular}

a Expressed as mean percentage cytotoxicity (triplicate wells) after $18 \mathrm{hr}$ of incubation as described under Methods. A negative value indicates fewer cpm released as compared to control wells (spontaneous release).

${ }^{b}$ Refers to the presence of $10 \mathrm{mM}$ methyl $\alpha$-D-galactopyranoside (Me $\alpha$-Gal) or methyl $\alpha$-D-glucopyranoside (Me $\alpha-\mathrm{Glc}$ ).

Table 2 presents the results of a typical experiment examining the effects of various concentrations of lectin on macrophage-mediated lysis of EAT cells at an effector/target ratio of 20:1. As can be seen, no significant lysis took place over $4 \mathrm{hr}$ of incubation. In contrast, 18-hr incubations produced macrophage-mediated cytotoxicity which was dependent upon lectin concentration in the assay. When varying effector to target ratios were studied in the lectin-dependent macrophage cytotoxicity assay, a 20:1 ratio was found to be optimal. Comparable levels of cytotoxicity at $18 \mathrm{hr}$ were seen in two additional experiments.

Figure 1 depicts an experiment to determine the effects of haptenic and nonhaptenic sugars on lectin-mediated macrophage cytotoxicity. The haptenic methyl $\alpha$-D-galactopyranoside inhibited completely the lectin-dependent macrophage lysis of EAT cells, whereas the nonhaptenic methyl $\alpha$-D-glucopyranoside had no effect on the assay.

As a further demonstration of the potential ligand function served by GS I lectin in macrophage-mediated cytolysis, FITC-conjugated GS I was incubated both with EAT target cells and with these same macrophage populations. As seen in Fig. 2, EAT cells (panel A) and macrophages (panel B) demonstrated FITC lectin binding. Specificity of fluorescent conjugate binding was demonstrated by the ability of low concentrations $(10 \mathrm{mM})$ of haptenic sugar to abolish the observed fluorescence.

TABLE 2

Lectin-Dependent Macrophage Cytotoxicity ${ }^{a}$ of EAT Cells

\begin{tabular}{rllccrc}
\hline & \multicolumn{5}{c}{ G. simplicifolia conc. $(\mu \mathrm{g} / \mathrm{ml})$} \\
\cline { 2 - 7 } $\begin{array}{c}\text { Time } \\
(\mathrm{hr})\end{array}$ & 0 & 1 & 3 & 10 & 30 & 100 \\
\hline 4 & 0 & 0 & 0 & 0 & 1 & 3 \\
18 & 0 & 1 & 3 & 30 & 44 & 38 \\
\hline
\end{tabular}

\footnotetext{
${ }^{a}$ Expressed as mean percentage cytotoxicity of triplicate wells at an E/T ratio of $20: 1$ at 4 and 18 hr of incubation as described under Methods.
} 


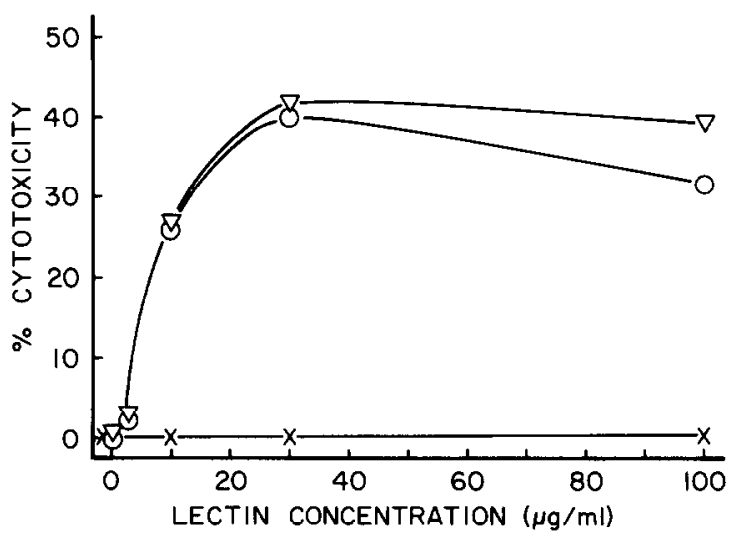

FIG. 1. Effects of haptenic and nonhaptenic sugars on GS I lectin-dependent, EAT-directed macrophage cytotoxicity. The assay was run at $\mathrm{E} / \mathrm{T}$ ratio of $20: 1$, and 18-hr incubation in the absence of sugar $(\mathrm{O}-\mathrm{O})$, in the presence of $10 \mathrm{~m} M$ methyl $\alpha$-D-galactopyranoside $(\times-\times)$ or $10 \mathrm{~m} M$ methyl $\alpha$-D-glucopyranoside $(\nabla-\nabla)$.

\section{DISCUSSION}

We have presented data which suggests that (i) the GS I lectin is not directly cytotoxic to the EAT cells over a broad range of concentrations and $18 \mathrm{hr}$ of incubation. This time period is not likely to be exceeded in the peritoneal cavity, where relatively rapid removal of foreign protein occurs. (ii) GS I lectin does not appear to activate complement, or induce complement-mediated lysis of EAT cells, (iii) the concomitant presence of both inflammatory macrophages and GS I lectin
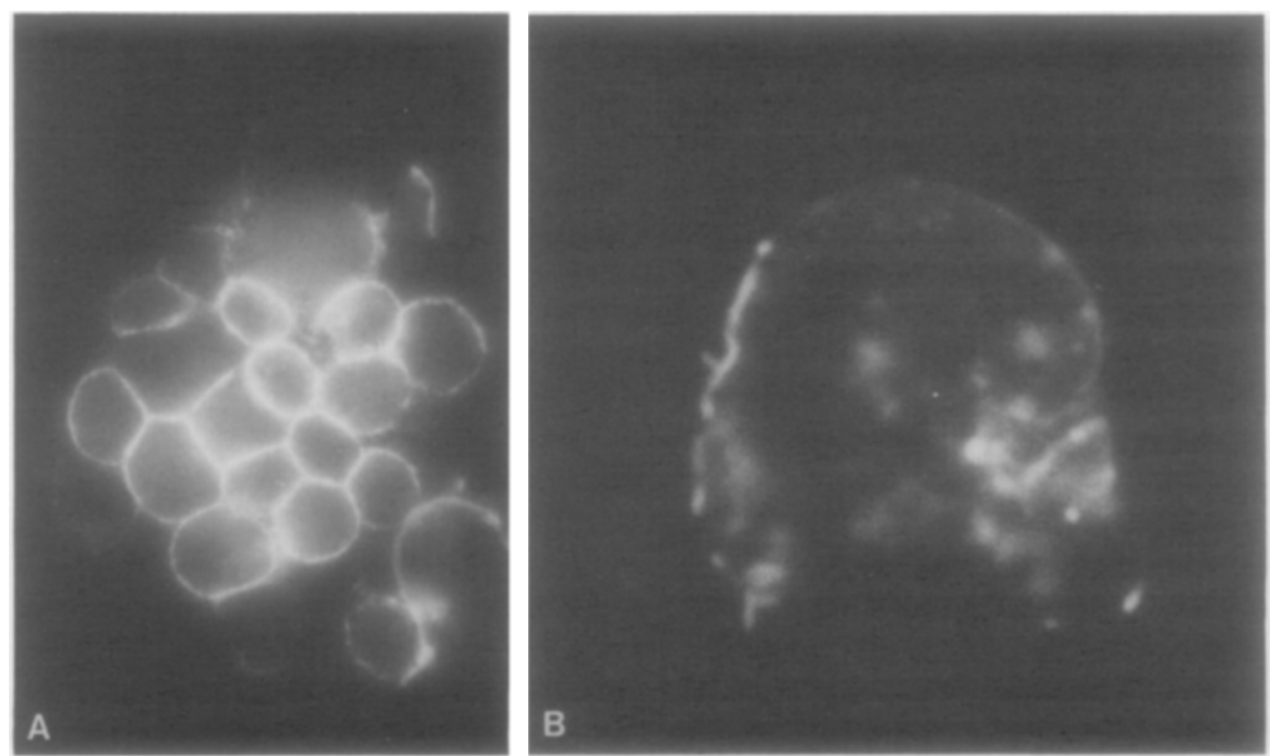

FIG. 2. FITC-GS I lectin binding to EAT cell agglutinate (A), $\times 400$; and stimulated macrophage (B), $\times 1000$. 
in vitro leads to tumor cell destruction, an effect completely abolished by presence of the lectin's haptenic sugar (methyl $\alpha$-D-galactopyranoside), and (iv) we have presented evidence of receptors for the FITC GS I lectin on the surfaces of both EAT cells and inflammatory macrophages, reinforcing the concept of the lectin serving a crucial bridging function in the demonstrated lectin-dependent macrophage interaction with EAT cells.

Kurisu and colleagues have recently reported on induction of macrophage-mediated tumor lysis by wheat germ agglutinin (11). In their report, they presented data showing that although concanavalin A, the kidney bean lectin (PHA), and pokeweed mitogen all were capable of serving the function of binding macrophages to tumor cells, only wheat germ agglutinin induced (or permitted) a cytolytic event to occur. It is of some interest that we have demonstrated (data presented in Ref. 7) that the trypsin-released and affinity-purified glycopeptide(s) from the macrophage cell surface which reacts with the GS I lectin also reacts with wheat germ agglutinin, concanavalin $\mathrm{A}$, phytohemagglutin, as well as Ricinus communis agglutinin I. Hopefully, further chemical analysis of the individual GS I and wheat germ binding macrophage surface glycoproteins in comparison to membrane glycoproteins which bind only concanavalin $\mathbf{A}$ or phytohemagglutinin will begin to provide some molecular rationale for induction (or permissiveness) of a macrophage cytolytic event from the standpoint of surface membrane binding phenomena.

Whether lectin-dependent, macrophage-mediated antitumor cytolytic activity is responsible for the observed protective effects of treatment with GS I lectin at the time of inoculation with EAT cells cannot be firmly concluded from the results of these experiments. However, it is a reasonable hypothesis which can be further subjected to test. Further studies designed to test additional alternative hypotheses, such as accelerated induction of T-lymphocyte-mediated cytotoxicity, and enhanced humoral immune responsiveness to the tumor are in progress.

\section{ACKNOWLEDGMENT}

The authors wish to thank Dr. David Keren for providing the $\mathrm{CH}_{50}$ complement assays.

\section{REFERENCES}

1. Hayes, C. E., and Goldstein, I. J., J. Biol. Chem. 249, 1904, 1974

2. Hayes, C. E., and Goldstein, I. J., J. Biol. Chem. 250, 6837, 1975.

3. Murphy, L. A., and Goldstein, I. J., J. Biol. Chem. 252, 4739, 1977.

4. Murphy, L. A., and Goldstein, I. J., Biochemistry 18, 4999, 1979.

5. Eckhardt, A. E., and Goldstein, I. J., In "Glycoconjugate Research" Edited by (J. D. Gregory and R. W. Jeanloz, Eds.), Vol. 2, pp. 1043-1045. Academic Press, New York, 1979.

6. Peters, B. P., and Goldstein, I. J., Exp. Cell. Res. 120, 321, 1979.

7. Maddox, D. E., Shibata, S., and Goldstein, I. J., Proc. Nat. Acad. Sci. USA 79, 166, 1982.

8. Tucker, S. B., Pierre, R. V., and Jordon, J. E., J. Immunol. Methods 14, 267, 1977.

9. Delmotte, F. M., and Goldstein, I. J., Eur. J. Biochem. 112, 219, 1980.

10. Levy, P. C., Shaw, G. M., and LoBuglio, A. F., J. Immunol. 123, 594, 1979.

11. Kurisu, M., Yamazaki, M., and Mizuno, D., Cancer Res. 40, 3798, 1980. 